\title{
Desejo e alienação na representação fílmica do trabalho de dublagem
}

\author{
Décio Torres Cruz \\ Universidade Federal da Bahia \\ Universidade do Estado da Bahia \\ deciotc@ufba.br
}

\begin{abstract}
Resumo
No início do século XX, nos primórdios do cinema, o trabalho humano na sociedade industrial já vinha sendo mostrado como fator de reificação e alienação em filmes como Metrópolis (1927), do diretor austríaco-alemão Fritz Lang, e Tempos modernos (1936), do diretor britânico Charles Chaplin. Mais recentemente, o trabalho humano em diferentes áreas ainda se apresenta como tema em diversos filmes. Embora nos encontremos em uma fase mais avançada da sociedade pós-industrial, e os mecanismos de controle tenham se modificado na sociedade tecnológica da informação, o processo de reificação e alienação parecem ainda vigorar em determinados ambientes. Abordarei o modo como as questões do desejo e da alienação são veiculadas em um filme que possui como temática o trabalho de tradução oral. Dessa forma, enfocarei a representação dessas questões na dublagem para televisão no filme Dias melhores virão (1989), de Carlos Diegues.
\end{abstract}

Palavras-chave: dublagem, alienação, desejo, anos 80, filme.

\begin{abstract}
In the early 20th century, at the dawn of cinema, human labor in industrial society had already been shown as a factor of reification and alienation in films such as Metropolis (1927), by the Austrian-German director Fritz Lang, and Modern times (1936), by British director Charles Chaplin. More recently, human labor in different areas still presents itself as a theme in several films. Although we are living at a later stage of post-industrial society and control mechanisms have been changed in our technological information society, the process of reification and alienation seem to be still in force in certain work environments. In this paper, I will discuss how alienation and desire are conveyed in a movie that portrays the work of voice artists and oral
\end{abstract}


translation as its theme. Thus, I will focus on the representation of these issues in dubbing for TV in the film Dias melhores virão (1989), by Carlos Diegues.

Keywords: dubbing, alienation, desire, 80s, film.

\section{Introdução}

A tradução aparece como tema em diversas obras fílmicas e literárias. O filme Lost in translation, de 2003, de Sofia Coppola, cujo título foi traduzido no Brasil como Encontros e desencontros, mostra o trabalho de uma intérprete de inglês para japonês. A ideia contida no título em inglês Lost in translation (literalmente traduzido como "Perdido na Tradução") percorre todo o filme com uma série de significados, mas enfoca principalmente os problemas das traduções culturais.

O trabalho de tradução também já foi tema da literatura, ou seja, como um escritor concebe o trabalho de tradução. No romance $L a$ nuit des temps (A noite dos tempos), do escritor francês René Barjavel, o ato tradutório constitui uma das peças-chave do enredo. Uma máquina de traduzir e a tradução adquirem o status de dois personagens centrais do romance, tornando-se duas peças fundamentais para o desenrolar da história, juntamente com outros personagens, cientistas e tradutores de diversos países. Assim, alguns aspectos da teoria da tradução são concebidos não pelo teórico de tradução, mas sob o ponto de vista daquele que é considerado o "criador de originais", que depois são traduzidos, ou seja, o próprio autor de ficção. Nesse romance, a tradução também é concebida como forma de poder, como motivo de disputa entre países e, por fim, como traição, gerando a possibilidade de um grande conflito internacional.

A concepção do trabalho do tradutor como possibilidade de geração de conflitos internacionais é também o tema do filme $A$ intérprete (2005), mescla de drama, ação e suspense, dirigido por Sydney Pollack. 
Já o filme brasileiro Dias melhores virão (1988) tem como foco o trabalho de tradução oral sob a forma de dublagem ${ }^{1}$. Além de abordar de forma bastante divertida o processo de dublagem em um estúdio profissional bastante precário, o filme focaliza questões culturais, nacionais e identitárias. Essas questões se aplicam tanto à área de tradução e dublagem como se adéquam à formação de futuros professores de línguas estrangeiras naquilo que se refere à conscientização do seu papel crítico, e não apenas de um mero disseminador de ideologias. Os autores do texto e o diretor do filme mesclam questões culturais e identitárias a questões linguísticas e nacionais que são bastante atuais no âmbito do ensino e aprendizagem de línguas estrangeiras e de bastante interesse para os estudos da Linguística Aplicada.

\section{Identidade e nação em Dias melhores virão}

A comédia Dias melhores virão, dirigida por Carlos (Cacá) Diegues, possui roteiro de Antonio Calmon, Vicente Pereira e Vinicius Vianna, e baseia-se em história de Antonio Calmon. O elenco é composto de atores renomados: Marília Pêra, como Marialva ou Mary Mattos, a cantora Rita Lee como Mary Shadow, Paulo José como Pompeu, Zezé Mota como Dalila, José Wilker como Wallace, Marilu Bueno como Adelaide, Patrício Bisso como Juanita, Lília Cabral como secretária, Paulo César Peréio como Pereira, Antonio Pedro como Salgado, Betina Viany como Janete, Benjamin Cattan como Ferreirão, Jofre Soares como Coronel, além de Aurora Miranda, interpretando ela mesma, Sandra Pêra, dentre outros. O filme ganhou dois prêmios no Festival de Cartagena, nas seguintes categorias: Melhor Atriz (Marília Pêra) e Melhor Roteiro. Em 1989, foi indicado pelo Brasil para a disputa do Oscar de Melhor Filme Estrangeiro.

A parte central da história se desenrola, na maior parte do tempo, em um estúdio de dublagem, com uma tela suja e remendada, onde os dubladores se revezam diante de um único microfone,

\footnotetext{
${ }^{1}$ É importante destacar que o trabalho de dublagem é exercido por atores profissionais, e não necessariamente por tradutores. Em inglês, o profissional dessa área é conhecido como voice artist, ou seja, artista da voz.
} 
demonstrando a precariedade desse trabalho na década de 1980, e onde uma série norte-americana para a televisão está sendo dublada. O filme conta a história de Marialva, uma dubladora de meia idade, que dubla seriados para a televisão e sonha em se tornar uma estrela internacional de Hollywood. Em seus devaneios, realidade e fantasia se misturam no desejo de se tornar uma atriz famosa. Ela conversa com entes fictícios, com a estrela principal, personagem da comédia americana seriada que ela dubla, e também com o fantasma de um namorado morto num acidente de moto ainda jovem, quando se exibia para ela. Tem um namorado casado, chamado Wallace (José Wilker), dono de uma agência de turismo que sempre promete largar a mulher depois que os filhos crescerem para ir com ela aos Estados Unidos.

Marialva também tem uma relação com seu chefe, Pompeu (Paulo José), o diretor do estúdio onde trabalha, que se apaixonou por ela. Sua melhor amiga e vizinha, Dalila (Zezé Mota), pede-lhe para ler e traduzir as cartas de um namorado americano. Numa das cartas, descobre um anúncio de um jornal americano procurando uma atriz latina para substituir uma personagem da série que ela dubla. Marialva resolve aproveitar a oportunidade. Quando descobre que Wallace morreu, apanha a passagem e o dinheiro que ele lhe havia prometido e se muda para os Estados Unidos, onde realiza o seu sonho.

Embora seja uma comédia, o filme, além do trabalho de dublagem, trata de vários assuntos sérios, como o trauma da perda de um ente amado; traição de esposa e promessas nunca cumpridas à amante; sonhos e desejos frustrados; as seções de tortura de um gato por um coronel aposentado, que alude às práticas perpetradas aos presos políticos da ditadura militar, vigente no Brasil até a década de 1980. Além disso, o filme apresenta a negação da identidade nacional e a desvalorização dos produtos brasileiros, inclusive nossa moeda, o que é revelado nas vozes de Wallace e no sonho de ser o outro. Esse sonho colonizado é engendrado pela indústria televisiva e cinematográfica hollywoodiana e efetivado na vontade da atriz brasileira de ser não aquela que dubla, mas aquela que interpreta, no desejo de sair da condição de periferia para o centro.

A vontade de ser o Outro está expressa na grafia dos próprios nomes, tanto dela quanto de seu amante, Wallace, que rejeita a condição de uma nacionalidade periférica até no nome. Na camiseta da agência, aparece como tio Wally, um nome estrangeiro, diminutivo de 
Wallace. Marialva prefere mudar seu nome para Mary Mattos, escrito com a letra "y", transformando a grafia do nome em português Mari no anglo-saxônico Mary. O sobrenome Matos (que alude à roça, campo, em uma referência à cidade de origem, Campos, no interior do Rio de Janeiro) adquire uma grafia estrangeirizada, com duas letras " $t$ ".

Além disso, a personagem que ela dubla, uma espécie de seu alter ego ou de identidade estendida, chama-se Mary Shadow, com um sobrenome também inventado em língua inglesa. Além da semelhança do nome inicial Mari/Mary de ambas as personagens, o sobrenome dela significa "sombra", invertendo os papéis, como se a americana fosse a sua sombra, uma companheira, ou seja, "um ser, humano ou animal, que costuma ir atrás de alguém, acompanhá-lo aonde quer que vá"2. Há ainda um contraste da palavra "sombra", que além das várias acepções, faz alusão à cópia, como reflexão de imagem. Além disso, implica "trevas, ausência de luz, escuridão, ausência de conhecimentos, cultura, instrução, liberdade, justiça; obscurantismo, ignorância, despotismo; algo que obscurece ou mancha a biografia ou a reputação de alguém"; significa ainda "o que entristece, preocupa, amedronta; mácula, nódoa"; e também é usada no sentido de "espírito desencarnado; alma, fantasma".

Todas essas acepções se aplicam à personagem Marialva, embora contrastem com a pureza da palavra "alva" presente no seu prenome. "Alva" significa "veste comprida de pano branco usada pelos padres nas cerimônias religiosas; primeira claridade da manhã; alba, alvor, aurora"; no sentido figurado, em Portugal, significa "primeiro momento; início, começo". Contudo, no sentido arcaico do século XIII, alude ainda à morte, significando "túnica branca que os condenados à morte vestiam quando levados para o patíbulo"3. Essa última acepção está relacionada à constante presença da morte em sua vida, na visão da "sombra" de seu ex-namorado, na repetição da cena de seu atropelamento, pelo qual ela se sente culpada, uma vez que ele se exibia para ela em cima de uma moto, como se ela estivesse condenada a levar essa sombra que lhe persegue até a morte.

\footnotetext{
2 As diversas acepções da palavra "sombra" e "shadow" foram retiradas, respectivamente, do Dicionário eletrônico Houaiss da língua portuguesa (CD-ROM) e do dicionário eletrônico Random House Webster's.

${ }^{3} \mathrm{Cf}$. Dicionário eletrônico Houaiss da língua portuguesa (CD-ROM).
} 
Em uma inversão causada pela reflexão dos nomes e dos egos que às vezes se fundem, Mary Shadow representa para ela um novo "começo", como se a ausência de luz da palavra "shadow" implicasse o seu oposto, a aurora, a primeira claridade da manhã que trouxesse um alento à insignificância de sua vida. Mary Shadow simboliza, assim, a possibilidade de uma nova vida no espaço do Outro, que é economicamente e, para ela, culturalmente mais importante e mais significativo, a realização de um sonho, a fusão e transformação total no Outro. Na verdade, esse desejo da personagem reflete um momento da nossa história e cultura, quando a emigração para o exterior havia se tornado uma febre, e a língua portuguesa passou a ser menosprezada, pois vários artistas passaram a compor e gravar músicas em língua inglesa. Devido a isso, alguns mudavam seus nomes próprios, adotando nomes estrangeiros, e alguns chegaram a conquistar reconhecimento internacional, como Morris Albert, pseudônimo de Maurício Alberto Kaisermann, paulista, cuja música Feelings (1975) vendeu mais de um milhão de cópias somente nos Estados Unidos ${ }^{4}$.

Nessa inversão de significados da imagem refletida, a parte do seu nome português/brasileiro contida na palavra "alva" pode significar aquilo que define a palavra "sombra". Sua condição periférica está associada a "ausência de conhecimentos, cultura, instrução", geralmente associada aos países subdesenvolvidos, como o Brasil era classificado na época.

Por sua vez, o significado de "ausência de liberdade, justiça; obscurantismo, ignorância, despotismo" está relacionado ao período histórico no qual o filme foi feito, quando ainda vivíamos os últimos momentos da ditadura militar aqui imposta a partir de 1964. Esse fato estaria conectado ao sentido de "trevas" como "algo que obscurece ou mancha a biografia ou a reputação de alguém", ou seja, pode ser interpretado como a "mácula, a nódoa" de sua história pessoal e da história de sua nação.

Assim, há um entrelace de histórias e significados, remetendo sempre àquilo "que entristece, preocupa, amedronta" e que a persegue

\footnotetext{
${ }^{4}$ Uma corte americana declarou depois que essa música era plágio de uma canção francesa de 1956, Pour Toi, de Loulou Gaste, obrigando Morris Albert a pagar 88\% dos royalties ao autor (Cf. http://pt.wikipedia.org/wiki/Morris_Albert. Acesso em: 28 mar. 2010.).
} 
como um espírito desencarnado, uma alma penada, reaparecendo nos fantasmas do ex-namorado e, depois, de seu amante. Esse significado também alude ao período histórico brasileiro, como uma metáfora dos fantasmas dos presos políticos mortos nas celas da ditadura militar, os espíritos dos mortos insepultos que vagueiam clamando justiça. Isso reaparece nas cenas já mencionadas de tortura do gato e do passarinho, feitas por um coronel reformado do exército, para quem a mãe de Dalila havia trabalhado até morrer, com quem ela vive e de quem agora cuida. O coronel aparece para abrir a porta para Marialva, encapuzado com uma máscara de tortura para não ser reconhecido, o que alude aos acontecimentos políticos da época. Mary Shadow, por sua vez, representa um fantasma que persegue Marialva constantemente, seguindo-a até em casa, alimentando o desejo de negar sua identidade e transformar-se no Outro, aqui metaforizado na figura do estrangeiro.

Apesar da comicidade da personagem, que pode ser comparada à comicidade de Macabéa, personagem de Clarice Lispector, ela aparece "entristecida, preocupada e amedrontada", mesmo quando sorri, em uma espécie de comicidade trágica.

Ao fazer o teste para dubladora, Marialva, em vez de repetir o texto da personagem em português, repete-o em língua inglesa, "I feel so happy today". Quando o diretor da agência diz que ela deve dizer o texto em português, ela argumenta que sabe, mas que tem facilidade de leitura labial e que "depois, em inglês, fica mais bonito". Essa cena demonstra não somente a negação da língua nacional, como se fosse menos bonita que a estrangeira, mas também o desejo de ser a atriz principal, e não apenas uma simples dubladora. Junto à negação da língua, está implícita a negação do produto nacional, que se revelou nos comportamentos antipatrióticos do final da década de 1970 e começo dos anos 1980, que contrastavam com o programa ufanista da ditadura militar na década de 1960 e começo dos anos 1970. Esse antiufanismo, gerado por uma rejeição dos valores militares, tiveram outras implicações socioeconômicas, fazendo com que os jovens passassem a vangloriar a cultura e os produtos norte-americanos em detrimento da nossa e que muitos almejassem a vida no exterior, tendo ocorrido um grande movimento de emigração.

Contudo, a invasão cultural norte-americana havia sido gestada muito anteriormente, na iniciativa Política de Boa Vizinhança do 
governo estadunidense, presidido por Franklin D. Roosevelt. Esse programa, apresentado durante a Conferência Pan-americana de Montevidéu, em dezembro de 1933, referia-se às relações políticas dos EUA com os países da América Latina entre 1933 até $1945^{5}$.

Essa política consistia basicamente em investimentos e venda de tecnologia norte-americana para os países latino-americanos, que, por sua vez, em troca pelos investimentos, deveriam apoiar a política norte-americana. O seu objetivo primário era evitar a intervenção militar que havia se tornado impopular nos EUA e a expansão do comunismo pela América Latina. Dessa Política da Boa Vizinhança surge o estreitamento das relações culturais entre os Estados Unidos e a América Latina e a consequente expansão do império norteamericano e das novas formas de neocolonialismo econômico e cultural.

Como parte dessa política, o cinema foi um fiel aliado e contribuiu para o trabalho de propaganda dos produtos norteamericanos e de sua política. Orson Welles e Walt Disney foram convocados a participar do programa de boa vizinhança e estreitar as relações entre os países por meio de filmes com temáticas latinoamericanas. Financiados por Nelson Rockefeller, coordenador dos Negócios Inter-Americanos e um dos principais acionistas da RKO Pictures, Welles deveria filmar o carnaval do Rio de Janeiro, mas acabou fazendo um documentário It's All True, que acabou sendo um fiasco e comprometendo a sua carreira. Por sua vez, o outro embaixador dessa política, Walt Disney, um anticomunista que havia delatado vários colegas ao HUAC, Comitê de Atividades Antiamericanas, cria o personagem malandro Zé Carioca, lançado no filme Saludos amigos, de 1943, que reaparece em The Three Caballeros (1945). A sempre sorridente dançarina-cantora Carmen Miranda foi convidada a ir aos Estados Unidos e divulgar a imagem do Brasil, deturpada no seu exotismo cultural, mesclando culturas distintas de países latinos em uma aberração exótica e arremedo

\footnotetext{
${ }^{5}$ Ao final da Segunda Guerra Mundial, quando Harry Truman assumiu a presidência do país.
} 
cultural $^{6}$, com seu inseparável turbante de frutas, que era obrigada a usar aonde quer que fosse.

Na década de 1960, a Política da Boa Vizinhança se consolida com a Aliança para o Progresso, que, nas palavras do presidente John Kennedy, era "um plano para transformar os anos 60 em uma década histórica de progresso democrático" para a pobre América hispânica e "trabalhar para eliminar a tirania do hemisfério", convocando Cuba e a República Dominicana a "se reunir à sociedade de homens livres"7. O filme de Cacá Diegues menciona esses fatos históricos de maneira sutil, mas de forma bastante explicitada no roteiro:

Por essa época, Ferreirão conseguira encontrar um raríssimo poster de The Three Caballeros com a ajuda de Fabiano Canosa, famoso colecionador, conhecido em Nova York como "the walking film archive". Este era um velho filme de Disney, com o Pato Donald, Zé Carioca e Panchito, esforço de Hollywood pela política de boa vizinhança do governo americano nos anos quarenta. Ferreirão mandara fixar o poster gigante na parede principal da sala de espera do

\footnotetext{
6 “As imagens hollywoodianas enfatizavam não só aspectos culturais latinoamericanos em geral, mas também um estereótipo de como o hemisfério norte percebia o hemisfério sul, gerando o mito até hoje de que México e Brasil são a mesma coisa, que no Brasil se fala espanhol e que Buenos Aires é a nossa capital. Os filmes de Carmen Miranda eram uma salada cultural que ia do vestido estilizado de baianas do acarajé, com turbantes que nenhuma brasileira jamais usou, até o chapéu mexicano que os seus músicos eram obrigados a usar. A América Latina deixava assim de ser uma região de proporções continentais, composta de diversos países com culturas e línguas distintas, para se tornar um imenso arremedo de um país único com uma única língua e uma única peculiaridade cultural: o exótico, que se manifestava em tipos divertidos, ridículos, subservientes e abobalhados, sempre dispostos a entreter e servir mansamente e humildemente a Tio Sam. Esse era o reverso da moeda, o ensino sobre o Brasil feito pelos americanos para a contemplação americana e européia, e que depois nos era trazido de volta para que chegássemos a nos perceber dessa forma e, ao nos vermos no espelho do império, passássemos a acreditar que nós éramos assim realmente, já que estava escrito nos filmes, e tudo que se escreve é verdade e Hollywood, com toda a sua santidade de paraíso de sagrados astros e estrelas míticas, jamais mentia" (CRUZ, 2004, p. 143-172).

${ }^{7}$ KENNEDY, John. F. Preliminary formulations of the Alliance for Progress' address by President Kennedy at a White House reception for Latin American diplomats and members of Congress, March 13, 1961. The Department of State Bulletin, XLIV, n. 1.136, April 3, 1961. p. 471-474.
} 
estúdio, em destaque na coleção de cartazes nacionais e estrangeiros que mantinha por ali (DIEGUES, 1990, p. 90).

Voltando à personagem Marialva, ela deseja tanto ser atriz que mesmo durante o seu trabalho de dublagem se recusa a dublar uma cena porque não está sentindo a motivação da personagem e pergunta ao seu chefe o que ela deverá usar de sua memória emotiva para se identificar criticamente com o seu personagem, em uma metalinguagem de teatro. Isso deixa Pompeu inseguro, pois passa a atribuir a ele características de um diretor de teatro, o que ele não é. Ainda assim, ele se encanta com a beleza e singularidade de Marialva. Pompeu, que havia sido um ator famoso, a elogia em seu primeiro trabalho. Ao voltar para casa, Marialva e Dalila tentam escolher um nome novo para ela, um nome de estrela, pois o dela não é. A escolha toma toda a atenção delas que chegam a ignorar um assalto que presenciam. As sugestões de nomes feitas por Dalila remetem sempre a nomes de estrelas de Hollywood, até chegar em Mary Mattos. A partir dessa escolha, Marialva diz em inglês "A star is born" ("Nasce uma estrela"), que é um título de dois filmes homônimos, um de 1954, dirigido por George Cukor, com Judy Garland e James Mason, e outro de 1976, dirigido por Frank Pierson, com Barbra Streisand e Kris Kristofferson. Em seguida, observa uma pinta no rosto de Mary Shadow que ela acha

um charme atraente da norte-americana, entende o gesto como uma sugestão de cumplicidade. Talvez de identidade quem sabe integração. Mary Mattos é a nova voz de Mary Shadow. Quem sabe Mary Mattos não é Mary Shadow Marialva pinta com a ponta de um lápis preto o sinal na face (DIEGUES, 1990, p. 40-41).

Ao ter a sua veia artística incentivada por Pompeu e escolhido sua nova identidade, seu novo nome artístico, Marialva vai à seleção de elenco de uma peça de teatro, na qual exigem alguém bem mais nova do que ela para interpretar a personagem Ceci, adaptação teatral de $O$ guarany, de José de Alencar. Sua amiga Dalila a estimula a desistir quando nota a presença de apenas adolescentes concorrendo ao papel, mas ela insiste, até ela própria se conscientizar da inadequação 
de sua idade. Decide não ir trabalhar e ter que enfrentar a vergonha da decepção pela rejeição devido à sua idade e volta para casa. Ao entrar, encontra a televisão ligada e, no seu delírio, a personagem que ela dubla, sentada na sala fazendo ginástica em frente à televisão, seguindo as instruções de Jane Fonda, como costuma fazer no seriado. Ela não se surpreende, como se estivesse acostumada a isso.

No desejo de ser a outra, Marialva imagina dialogar com a personagem que ela dubla e cuja vida, embora também mesquinha como a dela, aparenta a ilusão de segurança e conforto e a possibilidade de uma família feliz, o que ela tanto almeja. Nesse diálogo, referências ao seu trabalho de dubladora ficam explicitadas. A personagem Mary Shadow fica surpresa com a chegada de Marialva e lhe pergunta em inglês se ela não deveria estar trabalhando e as duas têm a seguinte conversa, misturando as línguas. Mary Shadow fala em inglês e Marialva responde em português:

- Aren't you supposed to be working today?

- Eu nunca vou ser uma estrela - responde Marialva agressivamente, desfazendo o sinal a lápis que plantou sobre o rosto direito, reproduzindo o de Mary Shadow.

- That's not the only way to be happy - Mary Shadow se aproxima suavemente de Marialva, um tom amigo, porém superior, dominando a relação dela com a sua voz brasileira.

- Ninguém nunca vai achar graça em mim - reclama Marialva com voz de choro.

- Somebody's in love with you - diz Mary Shadow olhando, pela janela, o grafite que Pompeu deixara na rua, outro dia.

- I mean, really in love, right?

- Love, love, love! - grita Marialva. - Todo mundo só pensa nisso? - Marialva se irrita:

- Fala em português, anda.

- I can't! - diz Mary Shadow.

- Eu estou aqui - tranquiliza Marialva. - Vai.

- Oh, yeah! - lembra a americana.

-Ok. Right?

- Valendo! - anuncia Marialva (DIEGUES, 1990, p. 85-87).

No trecho destacado do roteiro cinematográfico publicado em forma de livro pela editora Record, fica implícita a relação de poder, 
expressa linguisticamente, entre as duas personagens. A personagem Mary Shadow, que aparece como um fantasma na sala de Marialva e conversa com ela, embora num tom amigável, deixa entrever "um tom amigo, porém superior, dominando a relação dela com a sua voz brasileira". Assim, a língua portuguesa assume uma posição inferior, de subserviência à língua inglesa falada por Mary Shadow. Para atenuar essa diferença, Marialva pede a ela que fale em português, ao que a outra retruca que não sabe, até Marialva lembrá-la de que ela está ali para fazê-la falar em português.

Nesse discurso metalinguístico, é recriado o ambiente do estúdio de dublagem, onde até os problemas com sincronia e com a tradução de falsos cognatos aparecem, em situações engraçadas devido à má tradução do texto-fonte. Repetindo o bordão de seu diretor de dublagem, ela inicia a dublagem da fala de Mary Shadow gritando "Valendo!". Dessa forma, ela se apropria da voz da outra, de modo dessincronizado, e essa apropriação é uma maneira de compensação do seu sentimento de inferioridade em relação à outra língua e à outra vida.

Essa inferioridade é gestada ideologicamente pelo centro econômico mais potente, gerador de uma cultura que se sobrepõe sobre a nossa de forma colonizadora através dos meios de comunicação de massa. No caso específico, pelo cinema de Hollywood e pelos enlatados da televisão americana que dominam a grade de programação da televisão brasileira, aí representado pelo seriado The Mary Shadow show. A dublagem passa a constituir uma forma de apropriação do poder do outro, silenciando a sua voz em língua estrangeira de mais prestígio internacional e obrigando-a a falar a desprestigiada língua nacional.

Agora, a voz que sai da boca dessincronizada de Mary Shadow é a de Marialva, que a dubla:

- Esse cara, o Wallace, ele é bom amante de verdade? Hein?

Duas vezes? Três? Não, ele é apenas uma data, certo?

Mary Shadow se interrompe, substituindo a malícia da fofoca feminina pela surpresa:

- Data?

Marialva cai em si:

- Que data! Data não. Namoro, encontro, programa. 
Mary Shadow sorri do erro de tradução de sua dublagem, fenômeno a que já se acostumou. Com forte sotaque, mas empenho rítmico surpreendente, ela começa a cantar um velho fox de Noel Rosa:

- "O que eu sei somente é que você é um ente, que mente inconscientemente..."

Marialva a interrompe: [...]. (DIEGUES, 1990, p. 87).

O discurso metalinguístico do trecho aborda ainda as confusões de tradução, muito comuns naquela época, que aparecem exemplificadas com a tradução da palavra date por "data", em um contexto que exigiria outra escolha lexical da rubrica "relacionamento amoroso", que na gíria de hoje poderia equivaler a "namorico", "ficante". Erros de tradução eram frequentes, mostrando o despreparo de alguns tradutores da época e a falta de revisão. Esse fato gerava um repertório de piadas ocasionadas pelo desconhecimento de determinadas expressões da língua inglesa que eram traduzidas literalmente.

Por sua vez, a imprensa fazia uma crítica ferrenha a esses erros, sem levar em conta as condições de trabalho desses tradutores, só apontando suas falhas e nunca seus acertos. Muitas vezes, atribuíase, inclusive, aos tradutores as escolhas de títulos de determinados filmes como se fossem erros de tradução, escolhas essas feitas pelas agências distribuidoras com intuitos mercadológicos e sem nenhuma relação com a tradução do título original ${ }^{8}$. Hoje, com a profissionalização da profissão de tradutor e da abertura de vários cursos específicos para essa área, esses problemas são raros, embora ainda aconteçam, mas com menor frequência.

Voltando ao trecho destacado, vemos que a apropriação chega a tal ponto que ultrapassa os limites linguísticos e envereda pelo repertório da música nacional, por meio da introdução de uma música de Noel Rosa. Embora se trate de um produto nacional, o estilo é americano (fox, de foxtrot). Outra referência metalinguística à profissão de tradução aparece quando a atriz americana fala para Marialva que, se ela não a dublar, ela terá que usar legendas,

\footnotetext{
${ }^{8}$ Exemplo disso foi a tradução do título do filme Splendor in the Grass, retirado de um poema de Wordsworth, por $O$ clamor do sexo.
} 
mencionando as duas formas de tradução comuns a produtos midiáticos.

- Que música é essa? - pergunta surpresa. - Como é que você sabe uma música em português?

- I don't - responde Mary Shadow retomando a ginástica. Hey, you didn't dubb [sic] me, if you don't dubb [sic] me, I have to use subtitles.

- Desculpe, eu me distraí - justifica-se Marialva.

- Ok, let's try again - sorri a segura Mary Shadow.

- Valendo! - grita Marialva.

- Não sei - repete Mary Shadow com a voz de Marialva. E volta a cantar Noel e a fazer a ginástica da Jane Fonda (DIEGUES, 1990, p. 87-88).

Convencionou-se, aqui no Brasil, talvez devido ao tamanho da tela da televisão e ao nível educacional do público de televisão, que filmes de cinema fossem legendados e os da televisão, dublados. Embora na Europa a prática de dublagem seja comum para quase todos os filmes, a depender do país, aqui no Brasil, filmes dublados no cinema eram apenas aqueles dirigidos ao público infantil. Hoje, são comuns as duas versões para filmes dirigidos também ao público adulto, o que demonstra uma mudança de comportamento do público brasileiro e reflete uma tendência à preferência pela língua oral do que pela escrita, o que revela uma faceta de mudança cultural. Essa mudança pode indicar que as pessoas preferem concentrar sua atenção apenas nas imagens, sem ter que se concentrar na leitura de legendas, ou, até mesmo, pode apontar para uma infantilização do público, que teria se tornado mais preguiçoso para a leitura. Com a expansão dos canais a cabo ou via satélite da televisão fechada entre a baixa classe média brasileira, a prática da dublagem também aumentou nesse segmento, o que parece indicar ainda o baixo nível educacional e de leitura do público que prefere a tradução oral à escrita.

No seguinte trecho, aparece outro discurso metalinguístico, dessa vez envolvendo a análise da história vivida por Mary Shadow e a interferência da empregada Juanita (Patrício Bisso) nas suas decisões. Assim, a dubladora discute com a personagem que ela dubla os rumos da narrativa da sua história de vida fictícia, enquanto esta discute com a sua dubladora o rumo de sua vida. 
No aparelho de televisão ligado mas sem som, no centro da sala, Mary Shadow discute com Juanita o desaparecimento de Larry, seu marido, como nossos heróis haviam dublado recentemente. Marialva reconhece o episódio, comenta com maldade a situação.

- Você não devia deixar a Juanita se meter tanto na sua vida - intriga. - Não vai dar certo.

Nesse intercâmbio de reflexões sobre a vida da personagem fictícia (Mary Shadow) e da suposta personagem "real" (Marialva), surge um metadiscurso sobre os personagens fictícios do cinema, antecipando um tema que já havia aparecido no filme $A$ rosa púrpura do Cairo (1985), escrito e dirigido por Woody Allen.

- Sabe, quando eu era pequena - responde Mary Shadow com candura - ficava imaginando que de noite, depois que os cinemas fechavam, todos os personagens que haviam atuado nos filmes ficavam por ali, passeando pela platéia, comendo pipoca, batendo papo, conversando sobre suas aventuras. Eram piratas, detetives, princesas, vaqueiros, mulheres fatais, fantasmas dos filmes que passavam no cinema.

Esse metadiscurso surge na fala de Mary Shadow para alertar Marialva da condição de fantasma ocupado por Wallace na mente da dubladora, só que um tipo diferente de fantasma. Ele não é como o fantasma de seu ex-namorado da juventude, mas um fantasma de um personagem fictício, de filme. Essa relação do Wallace com um personagem cinematográfico aparece no próprio modo como ele se vê, se autonomeando Indiana Jones, um personagem e herói do cinema americano, embora Marialva o ache parecido com William Holden, outro ator hollywoodiano. Tudo nesse personagem é falso, como sua relação com Marialva. Até o nome de sua agência, Over the rainbow, grafada em inglês, alude ao filme $O$ mágico de $O z$ por meio de uma das músicas de sua trilha sonora. Assim, as identidades vão sendo ocupadas por fantasmas, tornando-se ocas, vazias de conteúdo.

- Não estou te entendendo - diz a desconfiada Marialva. 
Mary Shadow põe a mão sobre seu ombro, amiga e confiante:

- Esse cara, o Wallace, ele é um fantasma dos seus filmes. O outro não. O outro é real...

- Supõe-se que eu é que deva conhecer o seu texto responde Marialva se afastando desconfiada - e não você o meu.

Marialva fica paralisada no centro da sala, angustiada pela incerteza das palavras de Mary Shadow, um texto que bate fundo no seu coração.

Ela procura explicações:

- Por que você está me dizendo isso do Wallace e do Pompeu?

Mary Shadow sorri e levanta o som da televisão, no momento exato em que Juanita, com a voz de Dalila, responde a pergunta que ela lhe fizera naquele episódio, a propósito do desaparecimento do marido.

- Intuição feminina - diz a maliciosa Juanita (DIEGUES, 1990, p. 88-89).

Por fim, o próprio Wallace morre e torna-se literalmente um fantasma, que aparece para Marialva quando esta decide ir em busca da passagem e do dinheiro que ele tanto guardara para os dois viajarem à Disney World. Wallace representa o brasileiro entreguista, desiludido com sua nação e que não quer fazer nada para tentar mudar o status quo. Seu desejo é fugir para os Estados Unidos e assumir a identidade americana que ele tanto almeja, como pode ser visto neste trecho:

- Quando as crianças crescerem, a gente foge pros Estados Unidos. O Brasil não dá mais pé, acabou. Tinha que entregar pro americano transformar isso aqui em mais um estado deles, como o Alasca, Porto Rico [sic], o Havaí. Eu vou te tratar tão bem, boneca, que você vai viver o resto da vida como se todo dia fosse o dia do teu aniversário (DIEGUES, 1990, p. 105).

Como a contrapor esse desejo, em seguida é mostrado o diálogo entre Mary Shadow e Juanita, uma latino-americana que trabalha de empregada doméstica na sua casa. Enquanto a patroa reclama do esforço que tem que fazer na ginástica de Jane Fonda, a 
outra cantarola a canção I like to be in America, do musical West side story ${ }^{9}$, que contrapõe a vida de imigrantes de Porto Rico com a dos americanos e, ao mesmo tempo em que questiona, glorifica o sonho americano. Nesse trecho do filme, referências implícitas à Política da Boa Vizinhança e o temor da onda vermelha surgem quando a personagem Juanita diz: "essa senhora Jane Fonda vai acabar matando todas as mulheres americanas. Pensando bem, será que a senhora dona Jane Fonda não é uma agente russa?", o que se refere às posições esquerdistas declaradas da família Fonda (Henry, o pai, Peter e Jane, filhos) e alude ainda ao período macarthista, quando profissionais do cinema eram delatados por colegas por suas convicções políticas e acabavam ficando no ostracismo, sem trabalho. E quando Marialva vai para os Estados Unidos e substitui Juanita, uma das coisas que ela faz é colocar um turbante de Carmen Miranda na cabeça e cantar a cançãofox (ou samba-rumba) Chica-chica boom chic, de Harry Warren e Mack Gordon, gravada por Carmen Miranda em 1941, em outra alusão ao período e à Política da Boa Vizinhança. Ela não se transforma no personagem principal, mas na empregada, mais uma vez assumindo a condição periférica da América Latina.

O aparelho de televisão é um personagem vivo e presente na vida de Marialva. Sempre ligada, sem som, mesmo quando ela não está em casa, é uma presença constante, uma eterna companhia, como os fantasmas que a acompanham, ou um Big brother orwelliano em estado de eterna vigilância de seus atos.

Um outro aspecto relacionado ao filme é a não necessidade do dublador conhecer a língua estrangeira que requer dublagem. No filme, Marialva sabe inglês a ponto de reconhecer as falas da personagem que dubla através de leitura labial, enquanto sua amiga Dalila não sabe, não conseguindo ler as cartas do namorado escritas em inglês, tendo que recorrer a Marialva para a tarefa de tradução. Isso revela um dado da profissão de dublagem, que requer apenas que o profissional possua carteira de ator. O dublador estaria, assim, mais ligado à profissão de ator do que à de tradução.

A música é outra peça importante do filme, não só na trilha sonora. Além do mencionado foxtrot de Noel Rosa, cantado por

\footnotetext{
${ }^{9}$ De Leonard Bernstein e Stephen Sondheim, traduzido para o português, na versão cinematográfica, como Amor sublime amor.
} 
Aurora Miranda, outras músicas acompanham a narrativa, adicionando comentários às cenas, como algumas músicas de Roberto Carlos e a música Beatriz, de Chico Buarque e Edu Lobo, na voz de Milton Nascimento.

E é com a mescla de imagem e música que o filme finaliza. A imagem de Marialva/Juanita/Carmen Miranda em close-up é congelada, e, enquanto por sobre essa imagem rolam os créditos finais do filme, ouve-se a voz de Rita Lee (não mais personagem do filme, mas cantora), cantando Dias melhores virão, música dela e Roberto de Carvalho:

Sonhei que você me beijou num sofá de cetim

Acordei meio assim suspirando demais

Será que eu nasci pra sofrer

Segunda-feira vou mudar meu destino

Juro, hei de me dar bem

Juro, vou mandar cartão

Eu vi na TV uma atriz fazendo amor

Ela olhava o ator

Como eu olho você

Com cara de quem está no céu

Papel de boba só se for em Hollywood

Juro, eu fiz o que pude

Juro, vou pro Galeão

Eu juro, que dias melhores virão!

Assim, o filme termina, sintetizando o seu tema na letra da canção, que resume os sonhos e os desejos de um povo que precisa do espelho do Outro para se realizar.

\section{Considerações finais}

O filme Dias melhores virão, de Cacá Diegues, além de descrever de forma jocosa a dublagem e discutir questões culturais e identitárias no ambiente de trabalho da tradução oral, pode ainda ser utilizado como reflexão para a formação de profissionais de tradução e também para estudantes e futuros professores de línguas estrangeiras. As questões culturais e identitárias se mesclam às questões linguísticas 
e são pertinentes às discussões estabelecidas no âmbito do ensino e aprendizagem de línguas estrangeiras. Dessa forma, o filme pode ser utilizado como mecanismo de discussão na formação de tradutores/intérpretes/dubladores e professores de língua inglesa, pois apresenta determinados tópicos de interesse não só para futuros profissionais da área de tradução e dublagem, mas também para todos aqueles envolvidos com o campo da Linguística Aplicada.

\section{Referências}

A INTÉRPRETE. Disponível em:

<http://pt.wikipedia.org/wiki/A_Int\%C3\%A9rprete>. Acesso em: 28 mar. 2010.

BOA vizinhança. Disponível em:

<http://educaterra.terra.com.br/voltaire/mundo/eua_vizinhanca.htm〉. Acesso em: 28 mar. 2010.

CRUZ, Décio Torres. O cinema como linguagem pedagógica/ideológica para o ensino de línguas estrangeiras: (re)descobrindo a cultura do outro. In: MOTA, K.; SCHEYRL, D. (Orgs.). Recortes interculturais na sala de aula de línguas estrangeiras. Salvador: EDUFBA, 2004. p. 143-172.

. Tradução automática de textos sob a perspectiva da literatura. Estudos linguísticos e literários, Salvador, EDUFBA, v. 27-28, p. 209226, 2001.

DICIONÁRIO eletrônico Houaiss da língua portuguesa. São Paulo: Objetiva, Dez. 2001. 1 CD-ROM. Versão 1.0.

DIAS melhores virão. Direção: Carlos Diegues. Intérpretes: Marília Pêra, Zezé Mota, Rita Lee, Paulo José e outros. 1988. 1 DVD.

DIAS melhores virão. Disponível em:

<http://pt.wikipedia.org/wiki/Dias_Melhores_Vir\%C3\%A3o>. Acesso em: 28 mar. 2010. 
DIEGUES, Carlos. Dias melhores virão. Roteiro: Antonio Calmon, Vicente Pereira, Vinicius Vianna e Carlos Diegues. Argumento: Antonio Calmon. Rio de Janeiro: Record, 1990.

FILM.com. Dias melhores virão. Disponível em: <http://www.film.com/movies/dias-melhores-virao/14695101>. Acesso em: 28 mar. 2010.

GOOD neighbor policy. Disponível em: <http://en.wikipedia.org/wiki/Good_Neighbor_policy>. Acesso em: 28 mar. 2010.

(The) INTERPRETER. Disponível em:

<http://en.wikipedia.org/wiki/The_Interpreter>. Acesso em: 28 mar. 2010.

KENNEDY, John F. Preliminary Formulations of the Alliance For Progress' Address by President Kennedy at a White House Reception for Latin American Diplomats and Members of Congress, March 13, 1961. The Department of State Bulletin, XLIV, n. 1.136, April 3, 1961. p. 471-474.

MORRIS Albert. Disponível em:

<http://pt.wikipedia.org/wiki/Morris_Albert>. Acesso em: 28 mar. 2010.

RANDOM House Webster's Unabridged Dictionary. CD-ROM Version. New York: Random House, 1999. 1 CD-ROM.

REUTERS. Resenha: A Intérprete é suspense inteligente com Nicole Kidman. In: Portal Terra. Cinema e DVD. Disponível em: $<$ http://cinema.terra.com.br/ficha/0,,TIC-OI5320MNFilmes,00.htmlcole Kidman>. Acesso em: 28 mar. 2010.

LOST in Translation (film). Disponível em: <http://en.wikipedia.org/wiki/Lost_in_Translation_(film) > . Acesso em: 28 mar. 2010. 
Décio Torres Cruz

Recebido em: $27 / 05 / 2010$ Aceito em: $\quad 25 / 04 / 2011$

Title: Alienation and desire in the filmic representation of dubbing as a job 
Desejo e alienação na representação fílmica do trabalho de dublagem 